\title{
Identificação de Fontes de Resistência à Ferrugem da Folha do Trigo em Acessos de Aegilops tauschii
}

\author{
Ângela B. Almeida1, Márcia S. Chaves², Sandra P. Brammer² \& Maria Irene Baggio ${ }^{1}$ \\ ${ }^{1}$ Universidade de Passo Fundo, Cx. Postal 611, CEP 99001-970, Passo Fundo, RS, Brasil, e-mail: angelabiologia@yahoo.com.br; \\ 2Embrapa Trigo, Cx. Postal 451, CEP 99001-970, Passo Fundo, RS, Brasil, e-mail: mchaves@cnpt.embrapa.br
}

Autor para correspondência: Márcia Soares Chaves

ALMEIDA, A.B., CHAVES, M.S., BRAMMER, S.P. \& BAGGIO, M.I. Identificação de fontes de resistência à ferrugem da folha do trigo em acessos de Aegilops tauschii. Fitopatologia Brasileira 32:349-352. 2007.

\begin{abstract}
RESUMO
No Brasil, prejuízos ocasionados pela ferrugem da folha do trigo (Puccinia triticina) ocorrem anualmente. A incidência generalizada nas diferentes regiões produtoras varia em intensidade, dependendo das condições climáticas, da resistência genética das cultivares e do controle químico, sendo que a utilização de cultivares resistentes é o método mais eficiente de controle. Os genes que conferem resistência à ferrugem da folha em trigo são denominados $\operatorname{Lr}$ (leaf rust). Vários desses genes já foram identificados e mapeados. Alguns deles foram mapeados diretamente em genótipos hexaplóides, enquanto outros foram primeiramente encontrados em espécies afins, com menor nível de ploidia e, posteriormente, transferidos para o trigo cultivado. Das espécies afins, destaca-se a espécie diplóide Aegilops tauschii, doadora do genoma D do trigo cultivado, como uma importante fonte de genes de resistência. O objetivo desse trabalho foi avaliar a resistência à ferrugem da folha em acessos de Ae. tauschii, oriundos do Banco Ativo de Germoplasma da Embrapa Trigo (BAG - Passo Fundo, RS), para utilização das seleções nos programas de melhoramento. Quarenta acessos foram avaliados quanto à reação à raça SPJ-RS de Puccinia triticina e, destes, 25\% (10 acessos) apresentaram resistência. Os dados obtidos neste estudo servem como subsídio na escolha de acessos resistentes que poderão ser utilizados como genitores em programas de melhoramento genético a fim de incremento de resistência a esse patógeno.
\end{abstract}

Palavras-chave adicionais: Triticum aestivum, Puccinia triticina, Aegilops squarrosa.

\begin{abstract}
Identification of wheat leaf rust resistance accessions of Aegilops tauschii

In Brazil, losses caused by wheat leaf rust (Puccinia triticina) occur annually. The widespread incidence in the different producing areas varies in intensity, depending on climatic conditions, level of genetic resistance of the cultivars and efficacy of chemical control. The use of resistant cultivars is the most efficient control method, and the genes conferring resistance to leaf rust fungus are denominated $L r$. Several of these genes have already been identified and mapped. Some of them were mapped directly in hexaploid wheats, while others were initially found in related species, with lower ploidy level and later transferred to cultivated wheat. Among related species, Aegilops tauschii, the diploid species donor of the $\mathrm{D}$ genome of cultivated wheat, is indicated as an important source of resistance genes to leaf rust. The objective of this work was to evaluate the resistance of $A$. tauschii accessions from the Active Germplasm Bank of Embrapa Trigo (BAG - Passo Fundo, RS) to leaf rust, in order to incorporate this resistance in commercial varieties. The reaction to race SPJRS of Puccinia triticina was evaluated in forty accessions of $A$. tauschii and 25\% (10 accessions) were resistant. The data obtained in this study can help in choosing resistant accessions to be used as parents in breeding programs in order to increase resistance to the pathogen.
\end{abstract}

Additional keywords: Triticum aestivum, Puccinia triticina, Aegilops squarrosa.

A ferrugem da folha do trigo (Triticum aestivum L.) causada pelo fungo Puccinia triticina Erikss. (sin. Puccinia recondita Dietel \& Holw.) é provavelmente a mais importante doença fúngica que afeta esse cereal. No Brasil, epidemias desta moléstia inevitavelmente têm ocorrido, sendo que a severidade nas diferentes regiões produtoras pode variar de acordo com as condições climáticas, a época de início da epidemia, a resistência dos genótipos presentes

Parte da dissertação de Mestrado do primeiro autor. Universidade de Passo Fundo. Passo Fundo RS. 2006. e utilização de controle químico. Em genótipos suscetíveis, a severidade pode atingir níveis elevados comprometendo tanto o rendimento quanto a qualidade de grãos, os quais podem sofrer decréscimos acima de 30\%, podendo chegar até a 50\% ou mais (Roelfs et al., 1992; Reis et al., 1996; Chaves \& Barcellos, 2003).

O controle químico com fungicidas ainda é a forma mais utilizada para evitar as perdas ocasionadas pela doença. Este método, no entanto, tem grande impacto econômico, ambiental e social (Moraes-Fernandes, 1987). Para cultivares altamente suscetíveis, muitas vezes são necessárias duas aplicações de fungicidas, com custo de cerca de US\$ 30/ha por aplicação. Estima-se que, no Brasil, nos últimos 10 anos, 
o custo total da aplicação aérea de fungicidas para o controle de doenças foliares de trigo tenha sido de cerca de US\$ 90 milhões. Neste mesmo período, estima-se que as epidemias de patógenos foliares causaram prejuízos de cerca de US\$ 172 milhões aos produtores de trigo no Cone Sul da América do Sul (Germán et al., 2004).

O método mais eficiente e econômico para a redução das perdas provocadas pela ferrugem na lavoura é a utilização de cultivares resistentes (Nelson, 1973b). Esta prática, além de evitar as perdas causadas pelas moléstias, não aumenta os custos de produção, garantindo maior retorno aos produtores (Nelson, 1973a; Priestley \& Bayles, 1988).

Embora grande progresso no melhoramento para resistência à ferrugem da folha do trigo tenha sido alcançado nas últimas três ou quatro décadas, observa-se que houve um estreitamento na base genética do germoplasma atualmente disponível. Além disso, o surgimento de novas raças do patógeno implica na necessidade contínua de buscar novas fontes de resistência. Com o intuito de obter cultivares mais adaptadas e com resistência a essa moléstia, a introgressão de genes de espécies silvestres representa grandes potencialidades econômicas (Barbosa et al., 1993, Angra et al., 1996).

A maioria das espécies da tribo Triticeae são portadoras de resistência à ferrugem da folha (Zaharieva et al., 2001; Jones et al., 1995; Stepién et al., 2003), a qual é baseada em genes de resistência $\operatorname{Lr}$ (leaf rust). Entre as espécies silvestres que têm fornecido importantes genes de resistência $L r$ encontra-se Aegilops tauschii Coss. (sin. Aegilops squarrosa, Triticum tauschii, $2 \mathrm{n}=2 \mathrm{x}=14$, DD), a qual apresenta uma ampla distribuição ecológica e tem sido considerada uma das espécies diplóides mais importantes do grupo Triticum-Aegilops (Aguilar-Rincón et al., 2000; Assefa \& Fehrmann, 2004). No trigo cultivado (Triticum aestivum), dos 57 genes $L r$ descritos, oito são oriundos de Ae. tauschii: Lr21, Lr32, Lr39, Lr40, Lr41, Lr42 e Lr43 (Rowland \& Kerber, 1974; Kerber, 1987; Cox et al., 1994), os quais são efetivos durante todo o ciclo da planta, e $\operatorname{Lr} 22 a$ (Dyck \& Kerber; 1970; Rowland \& Kerber, 1974) o qual é descrito como gene de resistência de planta adulta.

Além disso, $A$. tauschii é uma espécie a que se tem dado particular atenção por produzir hexaplóides sintéticos (AABBDD), obtidos mediante cruzamentos interespecíficos diretos, podendo ser útil na transferência de genes de interesse (Moraes-Fernandes et al., 2000; Aguilar-Rincón et al., 2000). Assim, o objetivo desse trabalho foi avaliar a resistência à ferrugem da folha em acessos de $A$. tauschii para posteriores cruzamentos em programas de melhoramento, a fim de incorporar esta resistência em cultivares comerciais.

O experimento foi realizado no Laboratório de Biotecnologia e no Laboratório de Ferrugens do Trigo da Embrapa Trigo (Passo Fundo - RS) durante o período de março a junho de 2004. Foram avaliados 40 acessos de $A$. tauschii (Tabela 1), oriundos do Banco Ativo de Germoplasma (BAG) dessa instituição quanto à reação à ferrugem da folha. A raça de $P$. triticina selecionada para
TABELA 1 - Acessos de Aegilops tauschii e tipo de infecção em primeira folha de plântulas inoculadas com a raça SPJ-RS de Puccinia triticina, sob condições controladas. Embrapa Trigo, Passo Fundo, 2006

\begin{tabular}{|c|c|c|c|}
\hline Número & $\begin{array}{c}\text { Código do } \\
\text { Acesso }\end{array}$ & $\begin{array}{c}\text { Origem no BAG - } \\
\text { Embrapa Trigo }\end{array}$ & Tipo de Infecção ${ }^{1}$ \\
\hline 1 & RL5003 & Oídio 89 & 0 \\
\hline 2 & RL5491 & $180455 / 89$ & ; \\
\hline 3 & RL5492 & $180457 / 89$ & 3 \\
\hline 4 & RL5495 & $180458 / 89$ & 3 \\
\hline 5 & RL5496 & $180460 / 89$ & ; \\
\hline 6 & RL5497 & $30720 / 88$ & 0 \\
\hline 7 & RL5522 & $140510 / 83$ & 3 \\
\hline 8 & RL5523 & $247369 / 94$ & 3 \\
\hline 9 & RL5525 & $247375 / 94$ & 3 \\
\hline 10 & RL5527 & $247376 / 94$ & 3 \\
\hline 11 & RL5528 & $340010 / 91$ & 1 \\
\hline 12 & RL5531 & $340014 / 91$ & ; \\
\hline 13 & RL5536 & $340016 / 91$ & 3 \\
\hline 14 & RL5537 & $50744 / 82$ & 3 \\
\hline 15 & RL5538 & $247381 / 94$ & 3 \\
\hline 16 & RL5540 & $247382 / 94$ & 3 \\
\hline 17 & RL5543 & $340019 / 91$ & 3 \\
\hline 18 & RL5544 & $247383 / 94$ & 3 \\
\hline 19 & RL5547 & $340021 / 91$ & 3 \\
\hline 20 & RL5550 & $30769 / 88$ & ; \\
\hline 21 & RL5555 & $340028 / 91$ & 3 \\
\hline 22 & RL5556 & $340030 / 91$ & 3 \\
\hline 23 & RL5558 & $340031 / 91$ & 3 \\
\hline 24 & RL5559 & $247397 / 94$ & 3 \\
\hline 25 & RL5560 & 247399/94 & 3 \\
\hline 26 & RL5565 & $247401 / 94$ & 3 \\
\hline 27 & RL5570 & $247403 / 94$ & 3 \\
\hline 28 & NE $29227 \mathrm{C}$ & $135278 / 93$ & 3 \\
\hline 29 & RL 5422 & OIDIO 89 & 3 \\
\hline 30 & RL 5552 & $247407 / 94$ & 3 \\
\hline 31 & RL 5562 & $340033 / 91$ & 3 \\
\hline 32 & RL 5660 & $825019 / 98$ & 3 \\
\hline 33 & RL 5660 & $151653 / 85$ & 3 \\
\hline 34 & RL 5665 & $825023 / 98$ & ; \\
\hline 35 & RL 5668 & $825024 / 98$ & 3 \\
\hline 36 & RL 5684 & $825036 / 98$ & 3 \\
\hline 37 & RL 5695 & $825042 / 98$ & 3 \\
\hline 38 & RL 5771 & OIDIO 89 & ; \\
\hline 39 & RL 5793 & $625055 / 96$ & ; \\
\hline 40 & RL 5799 & OIDIO 89 & 3 \\
\hline
\end{tabular}

a inoculação foi SPJ-RS (Long \& Kolmer, 1989), por apresentar o mais amplo espectro de virulência ocorrente no Brasil até a realização dos testes. Esta raça é avirulenta 
em cultivares portadores dos genes $L r 3, L r 3 k a, L r 16, L r 20$, $L r 21$ e $L r 30$, e virulenta em cultivares que possuem os genes Lr1, Lr2a, Lr2c, Lr9, Lr10, Lr11, Lr14a, Lr14b, Lr17, Lr18, $L r 23, L r 24$ e $L r 26$ (Chaves \& Barcellos, 2006). O inóculo foi proveniente da coleção de raças de $P$. triticina mantido pela Embrapa Trigo.

Sementes dos acessos foram desinfestadas em hipoclorito de sódio a $1 \%$ e álcool etílico a $70 \%$, por 1 minuto cada, sendo em seguida colocadas em papel germitest umedecido com água destilada e posteriormente transferidas para geladeira, durante sete dias, a $4^{\circ} \mathrm{C}$, a fim de realizar a quebra da dormência das mesmas. Após o processo de vernalização, as sementes foram transferidas para germinador a $20^{\circ} \mathrm{C}$ durante 15 dias, a fim de promover a germinação e o desenvolvimento da parte aérea até esta atingir cerca de $10 \mathrm{~cm}$.

As plântulas foram então transferidas para copos plásticos contendo $150 \mathrm{~g}$ de solo nativo. A acidez foi corrigida com calcário e adicionou-se adubação recomendada pela análise de solo. Cada acesso foi semeado em três copos; cada copo contendo três sementes. Os copos foram dispostos completamente ao acaso e mantidos em casa-de-vegetação.

Urediniosporos da raça SPJ-RS em suspensão de óleo mineral Soltrol foram inoculados na primeira folha totalmente expandida das plântulas, após estas terem sido aspergidas com solução aquosa contendo, aproximadamente, duas gotas por litro de Tween $20^{\circledR}$. Após 16 horas em câmara úmida na ausência de luz e com saturação de umidade sem escorrimento à temperatura de $20^{\circ} \mathrm{C}$, as plântulas foram transferidas para casa-de-vegetação e distribuídas completamente ao acaso, sob condições naturais de luminosidade, umidade relativa na faixa de $60-80 \%$ e temperatura de cerca de $22 \pm 2^{\circ} \mathrm{C}$, tendo, por curtos períodos de tempo, esta atingido $30^{\circ} \mathrm{C}$. Juntamente com as plântulas dos acessos $A$. tauschii, foi inoculado, também em fase de plântula, um conjunto da série internacional de linhagens diferenciais para raças de $P$. triticina (Long \& Kolmer, 1989) e a cultivar de trigo Coxilha (testemunha suscetível). O tipo de infecção foi avaliado dez a 15 dias após a inoculação. O método para estimar o tipo de infecção foi o internacionalmente utilizado: $0, ;, 1,2$,
3, 4 (Tabela 2). Tipos de infecção 3 e 4 são considerados altos, correspondendo a suscetibilidade no hospedeiro, e os demais, a resistência (Roelfs et al., 1992).

Dos 40 acessos avaliados, 10 acessos (RL 5003, RL 5491, RL 5496, RL 5497, RL 5528, RL 5531, RL 5550, RL 5665, RL 5771, RL 5793) apresentaram resistência à ferrugem em estádio de plântula, totalizando um percentual de 25\% de acessos resistentes (Tabela 1). Estes resultados evidenciam a variabilidade de reação à Puccinia triticina dos acessos de $A$. tauschii testados em fase de plântula. A ocorrência de variabilidade genética quanto à reação a doenças tem sido salientada na literatura internacional por vários autores. No Brasil, mais de 700 entradas de várias espécies afins ao trigo foram testadas para resistência a septoriose (Moraes-Fernandes et al., 1980). Diversas espécies mostraram resistência em plântula, mas as entradas de $A$. tauschii foram aquelas que apresentaram melhor nível de resistência à essa moléstia, nesse estádio. Esses dados são concordantes com os resultados aqui relatados. Dessa forma, os acessos de $A$. tauschii que apresentaram resistência em plântula à ferrugem da folha constituem germoplasma valioso para cruzamentos com genótipos de trigo suscetíveis a Puccinia triticina a fim de incorporação de resistência genética qualitativa a esses materiais.

As reações dos acessos resistentes variaram de 0 a 1 , 0 que sugere a possibilidade de que os mesmos sejam portadores de genes diferentes. Diversos genes $L r$ foram relatados em $A$. tauschii. Dentre os 57 genes $L r$ conhecidos, os genes $L r 21$, $L r 32, L r$ 39, $L r 40, L r 41, L r 42$ e $L r 43$, podem estar presentes, uma vez que todos possuem origem em Ae.tauschii. Ainda, os acessos que apresentaram reação 3 poderão ser portadores do gene $L r 22 a$, que condiciona resistência de planta adulta, a qual apresenta reação de suscetibilidade em fase de plântula. A realização de testes específicos poderá prover informações mais precisas a esse respeito.

O conhecimento do fenótipo da reação do hospedeiro, do número de genes envolvidos em cada reação, do estádio de desenvolvimento da planta em que a resistência se expressa, das interações com o ambiente, dos mecanismos genéticos envolvidos e da combinação das resistências

TABELA 2 - Reação, tipos de infecção e sintomas de Puccinia triticina em primeira folha de plântulas de trigo (Adaptado de Roelfs et al., 1992)

\begin{tabular}{lcl}
\hline \hline Reação $^{1}$ & Tipo de infecção & \multicolumn{1}{c}{ Sintomas } \\
\hline & 0 & Nenhuma pústula ou outro sinal macroscópico de infecção \\
$\mathrm{R}$ & $;$ & Sem pústulas, com pequenos pontos cloróticos ou necróticos (hipersensibilidade) \\
& 1 & Pústulas diminutas, circundadas por clorose/ necrose \\
& 2 & Pústulas pequenas a médias, freqüentemente circundadas por clorose ou necrose \\
\hline S & 3 & Pústulas médias, que podem estar associadas com clorose \\
& 4 & Pústulas grandes, sem clorose \\
\hline
\end{tabular}

${ }^{1} \mathrm{R}=$ Resistência; $\mathrm{S}=$ Suscetibilidade 
qualitativa e quantitativa são aspectos de extrema valia nos programas de melhoramento, porque permitem utilizar os genes disponíveis de forma a obter uma proteção consistente contra o patógeno. Os resultados obtidos neste trabalho indicam que a utilização de A. tauschii como fonte de resistência pode ser uma estratégia promissora no controle da ferrugem da folha do trigo. Para que o potencial prático dessa estratégia possa ser avaliado, estudos adicionais para identificar os genes $L r$ presentes nos acessos resistentes, assim como para determinar sua herança, expressão e efeitos da interação entre eles deverão ser realizados. Técnicas de biologia celular e molecular poderão contribuir para o estudo destes fatores de resistência e para a identificação e transferência desses genes.

\section{REFERÊNCIAS BIBLIOGRÁFICAS}

AGUILAR-RINCÓN, V.H., SINGH, P.R., MOLINA-GALÁN, J.D. \& HUERTA-ESPINO, J. Inheritance of resistance to leaf rust in four synthetic hexaploid wheats. Agrociencia 34:235-246. 2000.

ANGRA, D.C., MARTINELLI, P., PRESTES, A.M. \& FERNANDES, M.I.B. Haplodiploidização de híbridos intergenéricos via gimnogênese. Brazilian Journal of Genetics 19(Supl.):124. 1996. (Resumo)

ASSEFA, S. \& FEHRMANN, H. Evaluation of Aegilops tauschii Coss. for resistance to wheat stem rust and inheritance of resistance genes in hexaploid wheat. Genetic Resources and Crop Evolution 51:663-669. 2004.

BARBOSA, M.M., PRESTES, A.M. \& ANGRA, D.C. Agropyron como fonte de resistência à mancha bronzeada do trigo. Fitopatologia Brasileira 18:335-347. 1993.

CHAVES, M. S. \& BARCELLOS, A. L. Situação das ferrugens do trigo no Brasil e comportamento das cultivares comerciais em 2000, 2001 e 2002. . In: Seminario Internacional Resistencia a Royas en Trigo, 2003, La Estanzuela. Seminario Internacional Resistencia a Royas en Trigo - Resumenes. La Estanzuela: INIA, p. 2. 2003.

CHAVES, M.S. \& BARCELLOS, A.L. Especialização fisiológica de Puccinia triticina no Brasil em 2002. Fitopatologia Brasileira 31:5762. 2006.

COX, T.S., RAUPP W.J. \& GILL, B.S. Leaf rust-resistance genes Lr41, Lr42 and Lr43 transferred from Triticum tauschii to common wheat. Crop Science 34:339-343. 1994.

DYCK, P.L. \& KERBER, E.R. Inheritance in hexaploid wheat of adult plant leaf rust resistance derived from Aegilops squarrosa. Canadian Journal of Genetics and Cytology 12:175-180. 1970.

GERMAN, S., KOHLI, M.M., CHAVES, M.S., BARCELLOS, A.L. NISI, J., ANNONE, J., MADARIAGA, R. \& VIEDMA, L. Breakdown of resistance of wheat cultivars and estimated losses caused by recent changes in the leaf rust population in South America. Proceedings, $11^{\circ}$.
International Cereal Rusts \& Powdery Mildews Conference, Norwich. 2004. p. 21. (Abstract)

JONES, S.S., MURRAY, T.D. \& ALLEN, R.E. Use of alien genes for the development of disease resistance in wheat. Annual Review Phytopathology 33:429-443. 1995.

KERBER, E.R. Resistance to leaf rust in hexaploid wheat: $L r 32$ a third gene derived from Triticum tauschii. Crop Science 27:204-206. 1987.

LONG, D.L. \& KOLMER, J.A. A North American system of nomenclature for Puccinia recondita f. sp. tritici. Phythopathology 79:525-529. 1989.

MORAES-FERNANDES, M.I.B., FERNANDES, J.M.C., PICININI, E.C., AITA, L. \& SARTORI, J.F. Transferência de genes de resistência a Septoria nodorum (Berk.) de espécies afins para o trigo. Resumos, Reunião Anual de Pesquisa de Trigo, Porto Alegre, RS. 1980. pp. 130-140.

MORAES-FERNANDES, M.I.B. Perspectivas da biotecnologia para o melhoramento de plantas. Pesquisa Agropecuária Brasileira 22:881896. 1987.

MORAES-FERNANDES, M.I.B., ZANATTA, A.C.A., PRESTES, A.M., CAETANO, V.R., BARCELLOS, A.L., ANGRA, D.C. \& PANDOLFI, V. Cytogenetics and immature embryo culture at Embrapa Trigo breeding program: transfer of disease resistance from related species by artificial resynthesis of hexaploid wheat (Triticum aestivum L. em Thell). Genetics and Molecular Biology 23:10511062. 2000.

NELSON, R. R. Introduction. In: Nelson, R.R. (Ed.) Breeding Plants for Disease Resistance. Pennsylvania PA. The Pennsylvania State University Press. 1973a. pp. 3-12.

NELSON, R.R. The meaning of disease resistance in plants. In: Nelson, R.R. (Ed.) Breeding Plants for Disease Resistance. Pennsylvania PA. The Pennsylvania State University Press. 1973b. pp. 13-25.

PRIESTLEY, R.H. \& BAYLES, R.A. The contribution and value of resistant cultivars to disease control in cereals. In: Clifford, B.C. \& Lester, E. (Eds.) Control of Plant Diseases: Costs and Benefits. Oxford UK. Blackwell Scientific Publications. 1988. pp. 53-65.

REIS, E.M., CASA, R.T. \& FORCELINI, C.A. Relação entre a severidade e a incidência da ferrugem da folha do trigo, causada por Puccinia recondita f. sp. tritici. Fitopatologia Brasileira 21:369-372. 1996.

ROELFS, A.P., SINGH, R.P. \& SAARI, E.E. Rust Diseases of Wheat: Concepts and methods of disease management. Mexico, D. F. CIMMYT. 1992.

ROWLAND, G.G. \& KERBER, E.R. Telocentric mapping in hexaploid wheat of genes for leaf rust resistance and other characters derived from Aegilops squarrosa. Canadian Journal of Genetics and Cytology 16:137- 144. 1974.

STEPIÉN, L., GOLKA, L. \& CHELKOWSKI, J. Leaf rust resistance genes of wheat: identification in cultivars and resistance sources. Journal Applied Genetics 44:139-149. 2003.

ZAHARIEVA, M., MONNEVEUX, P., HENRY, M., RIOVAL, R. \& VALKOUN, J. Evaluation of a collection of wild wheat relative Aegilops geniculata Roth and identification of potential sources for useful traits. Euphytica 119:33-38. 2001. 